\title{
Meta-analysis: Early Age at Natural Menopause and Risk for All-Cause and Cardiovascular Mortality
}

\author{
Luyao Huan, ${ }^{1}$ Xiangling Deng, ${ }^{1}$ Mengyang He, ${ }^{1}$ Shunhong Chen $\mathbb{D}^{2},{ }^{2}$ and Wenquan Niu ${ }^{3}{ }^{3}$ \\ ${ }^{1}$ Graduate School, Beijing University of Chinese Medicine, Beijing, China \\ ${ }^{2}$ Department of Emergency, Affiliated Nanping First Hospital, Fujian Medical University, Nanping, Fujian, China \\ ${ }^{3}$ Institute of Clinical Medical Sciences, China-Japan Friendship Hospital, Beijing, China
}

Correspondence should be addressed to Shunhong Chen; 765487209@qq.com and Wenquan Niu; niuwenquan_shcn@163.com

Received 17 October 2020; Revised 10 February 2021; Accepted 1 March 2021; Published 16 March 2021

Academic Editor: Susan $\mathrm{Hu}$

Copyright (C) 2021 Luyao Huan et al. This is an open access article distributed under the Creative Commons Attribution License, which permits unrestricted use, distribution, and reproduction in any medium, provided the original work is properly cited.

Aims. The aim of this meta-analysis was to comprehensively evaluate the association of early age at natural menopause with the risk for all-cause and cardiovascular mortality. Methods. Literature retrieval was done on August 4, 2020. Article selection and data extraction were completed independently and in duplicate. Early age at natural menopause was grouped into premature menopause ( $<40$ years), early menopause (40-44 years), and relatively early menopause (45-49 years). Effect-size estimates are summarized as hazard ratio (HR) or relative risk (RR) with $95 \%$ confidence interval (CI). Results. Sixteen articles involving 321,233 women were meta-analyzed. Overall analyses revealed a statistically significant association of early age at natural menopause with all-cause mortality risk $\left(\mathrm{HR}_{\text {adjusted }}=1.08,95 \% \mathrm{CI}: 1.03\right.$ to $1.14, P=0.002 ; \mathrm{RR}_{\text {adjusted }}=1.05,95 \% \mathrm{CI} 1.01$ to 1.08 , $P=0.005)$, but not with cardiovascular mortality risk. In dose-response analyses, the association with all-cause mortality was significant for premature menopause with $\left(\mathrm{HR}_{\text {adjusted }}=1.10 ; 95 \% \mathrm{CI}: 1.01\right.$ to $\left.1.21 ; P=0.034\right)$ and without $\left(\mathrm{RR}_{\text {adjusted }}=1.34 ; 95 \%\right.$ CI: 1.08 to $1.66 ; P=0.007)$ considering follow-up intervals. As for cardiovascular mortality, marginal significance was noted for premature menopause after considering follow-up intervals ( $\mathrm{HR}=1.09 ; 95 \% \mathrm{CI}$ : $1.00-1.19 ; P=0.045)$. Subgroup analyses indicated that gender, country, and follow-up periods were possible causes of heterogeneity. There was an overall low probability of publication bias. Conclusions. Our findings indicate that premature menopause is a promising independent risk factor for both all-cause and cardiovascular mortality.

\section{Introduction}

Menopause is defined as the cessation of spontaneous menses for 12 months, marking the end of a woman's reproductive life [1], and it typically occurs between the ages of 49 and 52 years [2]. An estimated $5 \%$ women experience early menopause (menopause onset within 40 to 45 years of age) [3], and $1 \%$ women experience premature menopause (menopause onset before 40 years of age) $[4,5]$. It is well known that the onset age of menopause is an indicator of reproductive aging, general health, and somatic aging [6]. Evidence from epidemiologic and clinical studies has demonstrated that early age at natural menopause is associated with an enhanced risk for all-cause and cardiovascular mortality [7, 8]. In 2016, Gong and colleagues conducted a meta-analysis of 10 articles, by showing that women who experienced the earliest age natural menopause had a slightly increased all-cause mortality risk [8]. Another review by Muka and colleagues recorded an enhanced risk of cardiovascular mortality and overall mortality in women who had experienced premature or early-onset menopause [9]. Although the association between early age at natural menopause and mortality has been widely evaluated in current medical literature [9-12], there is no definite consensus on this association, possibly due to populations of different races or ethnicities, individually underpowered studies, and lack of adjusting for confounding factors. Given the accumulating data after the year $2016[8,9,13]$, a more comprehensive evaluation of this association and exploration of possible reasons behind previously inconsistent reports are necessary.

To fill this gap in knowledge and yield more information for future research, we conducted a comprehensive meta- 
analysis by synthesizing the results of prospective studies that have evaluated the association of early age at natural menopause with all-cause and cardiovascular mortality.

\section{Materials and Methods}

This meta-analysis was complied with the guidelines of the Preferred Reporting Items for Systematic Reviews and Meta-analyses (PRISMA) statement [14], and the PRISMA checklist is summarized in Supplementary Table 1.

In this meta-analysis, as all data were extracted from previous published studies, ethical approval and informed consent are not required.

2.1. Search Strategy. We completed literature search as of August 4, 2020, by reviewing PubMed, HuGE Navigator, EMBASE (Excerpt Medica Database), and Web of Science databases. Only published articles written in the English language were considered in the current meta-analysis. The following medical subject heading terms were used: (premenopausal OR early menopause OR perimenopausal OR premature menopause OR menopause OR late menopause OR natural menopause OR postmenopause OR age at menopause OR menopausal age) [Title/Abstract] AND (cardiovascular risk OR coronary heart disease OR cardiovascular disease OR cardiovascular OR all-cause mortality OR cardiovascular mortality) [Title/Abstract]. The reference lists of retrieved articles were also hand searched for potential missing hits.

Two investigators (L.H. and X.D.) independently reviewed all retrieved articles and carefully assessed preliminary eligibility based on the title and abstract, as well as full text when necessary.

2.2. Inclusion and Exclusion Criteria. We restricted our analysis to articles that fulfilled the following inclusion criteria: (i) natural menopause; (ii) without estrogen therapy; (iii) multivariate-adjusted hazard ratio (HR) or relative risk (RR) with 95\% confidence interval (CI) for quantifying the association of age at natural menopause with cardiovascular or all-cause mortality; (iv) prospective design; (v) all-cause mortality verified by death certificates or medical records; (vi) study subjects free of major underlying diseases.

Articles were excluded if they focused on treatment, survival, or surgical menopause, or lacked control groups, or if they were case report or case series, editorial, narrative review, letter to the editor or correspondence, and nonEnglish articles.

2.3. Data Extraction. Two investigators (L.H. and X.D.) independently extracted data from each qualified article, which were typed into a standardized Excel spreadsheet, including the following items: name of first author, publication year, country where study was conducted, sample size, method for mortality ascertainment, baseline age, follow-up period, study design, study type, numbers of deaths, effect-size estimate, and other traditional risk factors, where available, including education, body mass index (BMI), and estrogen therapy. Any disagreement was resolved by a joint reevalua- tion of original article and, when necessary, was adjudicated by a third author (W. N.).

2.4. Quality Appraisal. The quality of the included cohort studies was appraised by means of the NOS (NewcastleOttawa Quality Assessment Scale) [15], which is calculated on the basis of three major components: selection of the groups of study (0-4 points), quality of the adjustment for confounding (0-2 points), and ascertainment of the exposure or outcome of interest in the case-control or cohorts, respectively (0-3 points). The maximum score is 9 points, which represents the highest methodological quality.

2.5. Statistical Analyses. We employed the STATA software (Stata Corp, College Station, TX, version 14.1 for Windows) for statistical analyses. The effect-size estimates for the association of early age at natural menopause with the risk for cardiovascular or all-cause mortality were summarized as HR or RR with $95 \%$ CI under the random-effects models.

The inconsistency index $\left(I^{2}\right)$ was used to assess betweenstudy heterogeneity, and it represents the per cent of observed diversity between studies that is a consequence of heterogeneity other than a chance observation. Significant heterogeneity is recorded if the $I^{2}$ is over $50 \%$, and a higher value denotes a higher degree of heterogeneity.

As there are various sources of heterogeneity, a wide panel of subgroups analyses were conducted by region, follow-up period, and age at menopause, respectively. We quantified the probability of publication bias by means of the Begg's funnel plots [16] and Egger regression asymmetry tests [17]. The trim-and-fill method was also used to estimate the number of potentially missing studies in the current meta-analysis. Significant publication bias is recorded if the probability of Egger's tests is below $10 \%$.

\section{Results}

3.1. Eligible Studies. After searching four public databases using predefined subject heading terms, we obtained a total of 4,472 articles, and 16 of them involving 321,233 women that assessed the association of early age at natural menopause with all-cause or cardiovascular mortality were eligible for inclusion in the current meta-analysis [12, 18-31].

The detailed selection process is presented in Figure 1.

3.2. Study Characteristics. Out of 16 eligible articles, only cardiovascular mortality was reported by 2 articles [25, 26], allcause mortality by 7 articles [19, 23, 24, 27-29, 31], and both by 7 articles $[10,12,18,20-22,30]$. Ten studies [10, 18-23, $25,26,30]$ reported HR as effect-size estimates, and RR by 6 studies [12, 24, 27-29, 31], as shown in Table 1. According to statistical methods used, 14 articles $[10,12,18-23,25-27$, 29-31] used Cox proportional hazards model, 1 article [24] used Poisson regression procedures, and 1 article [28] used logistic regression model (Table 2). The NOS scores ranged from 5 to 8 (Table 3 ).

According to age at menopause, we divided study subjects into four subgroups: (i) younger than 40 years (premature menopause); (ii) 40-44 years (early menopause); (iii) 45-49 years (relatively early menopause); (iv) 49-52 years 


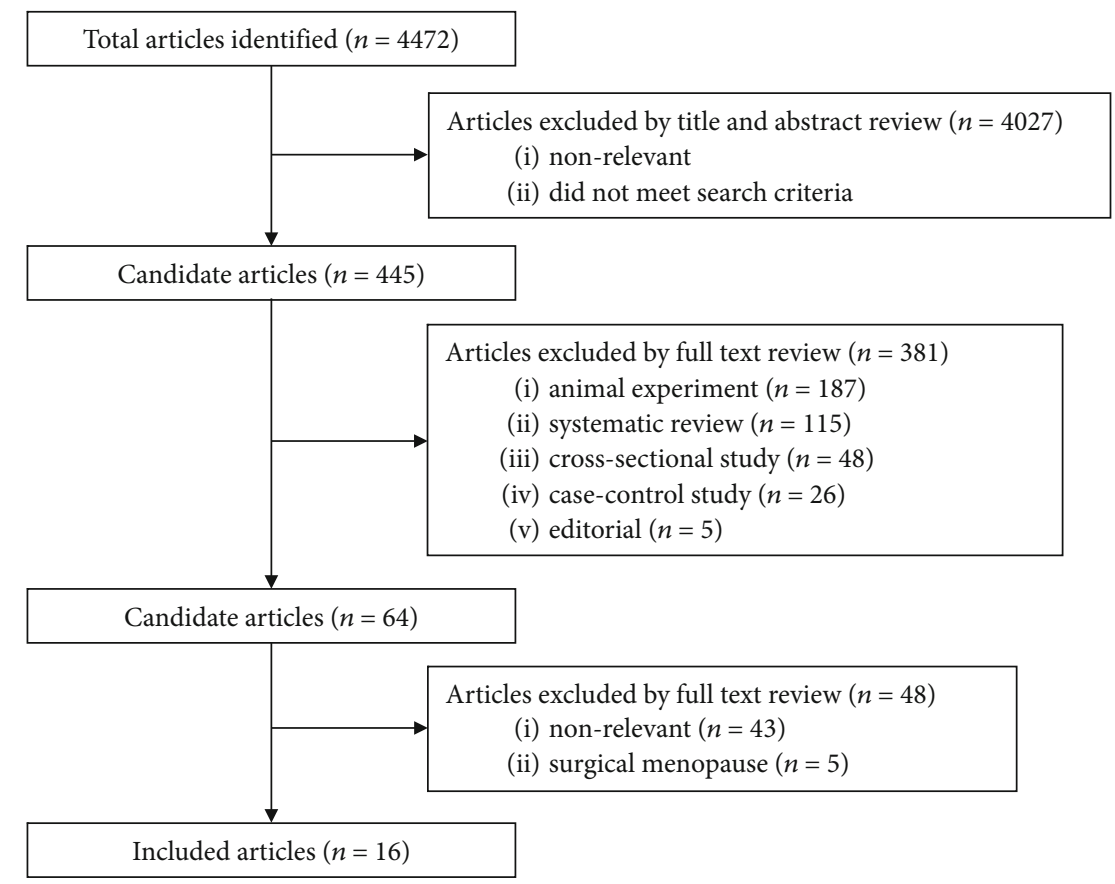

FIGURE 1: Flow chart of records retrieved, screened, and included in this meta-analysis.

(reference category). According to median follow-up periods (in years), we divided data into two subgroups: (i) less than 13.8 years (HR) $[19,22,23,25,30]$, less than 16.5 years (RR) $[12,24,29]$; (ii) more than or equal to 13.8 years (HR) $[10,18,20,21,26]$, more than or equal to 16.5 years (RR) $[27,28,31]$. In terms of location, we grouped studies into three groups: America [12, 19-22, 24, 27-29], Europe [26, $31]$, and Asian [10, 18, 23, 25, 30].

3.3. Overall Analyses. After pooling the results of all eligible articles together, we observed a statistically significant association of early age at natural menopause with an increased risk for all-cause mortality (unadjusted $\mathrm{HR}=1.12$, 95\% CI: 1.05 to $1.19, P<0.001$; adjusted $\mathrm{HR}=1.08,95 \% \mathrm{CI}: 1.03$ to 1.14 , $P=0.002$; unadjusted $\mathrm{RR}=1.03,95 \% \mathrm{CI}: 1.00$ to $1.06, P=$ 0.026 ; adjusted $\mathrm{RR}=1.05,95 \% \mathrm{CI}: 1.01$ to $1.08, P=0.005$ ) (Table 4). By contrast, no statistical significance was observed for the association between early age at natural menopause and cardiovascular mortality (unadjusted $\mathrm{HR}=1.04,95 \%$ CI: 1.00 to $1.13, P=0.385$; adjusted $\mathrm{HR}=1.01,95 \% \mathrm{CI}: 0.95$ to $1.09, P=0.682$; adjusted $\mathrm{RR}=1.08,95 \% \mathrm{CI}$ : 0.77 to 1.51 , $P=0.652$ ) (Table 4). For all-cause mortality, there was no heterogeneity with the $I^{2}$ of $45.6 \%$ for HR, but there was significant heterogeneity with the $I^{2}$ of $60.7 \%$ for RR. For cardiovascular mortality, there was no significant evidence of heterogeneity, with the $I^{2}$ of $42.1 \%$ for HR and $0.0 \%$ for RR.

3.4. Publication Bias. The possibility of publication bias was illustrated using the Begg's funnel plots for the association of early age at natural menopause with all-cause (Figure 2) and cardiovascular (Supplementary Figure 1) mortality, respectively, and they seemed symmetric. As further revealed by the Egger's tests, in studies reporting $\mathrm{HR}$, there was no evidence of publication bias for all-cause mortality $(P=0.746)$ and cardiovascular mortality $(P=0.782)$. By contrast, in studies reporting $\mathrm{RR}$, there was strong evidence of publication bias for all-cause mortality $(P=0.010)$, yet no publication bias for cardiovascular mortality $(P=0.456)$.

As reflected by the filled funnel plots, one and six additional studies were separately required for the relationship between all-cause mortality and early age at natural menopause in studies reporting $\mathrm{HR}$ and RR. For cardiovascular mortality, no study was missing for studies reporting HR and RR.

After adjusting for potential missing studies, effect-size estimates were still statistically significant for all-cause mortality $(\mathrm{HR}=1.08,95 \% \mathrm{CI}: 1.03$ to $1.14, P=0.002)$. On the contrary, even if the funnel plots were further filled to make the cardiovascular mortality plot symmetric, after adjustment for potential missing studies, effect-size estimates were not statistically significant for cardiovascular mortality $(\mathrm{HR}=1.01,95 \% \mathrm{CI}: 0.95$ to $1.09, P=0.682 ; \mathrm{RR}=1.08,95 \%$ CI: 0.77 to $1.51, P=0.652$ ).

3.5. Subgroup Analyses. We subsequently conducted a large panel of subgroup analyses, because the $I^{2}$ suggested the possible existence of between-study heterogeneity (Table 4).

By geographic location, in studies reporting HR, the association between early age at natural menopause and all-cause mortality was statistically significant in Asian countries (HR $=1.11,95 \% \mathrm{CI}: 1.03$ to $1.18, P=0.004)$, but not in American countries $(\mathrm{HR}=1.05,95 \% \mathrm{CI}: 0.96$ to $1.15, P=$ 0.268 ). In studies reporting $R R$, the association between early age at natural menopause and all-cause mortality was statistically significant in both American countries $(\mathrm{RR}=1.08$, 95\% CI: 1.02 to $1.15, P=0.010)$ and European countries 


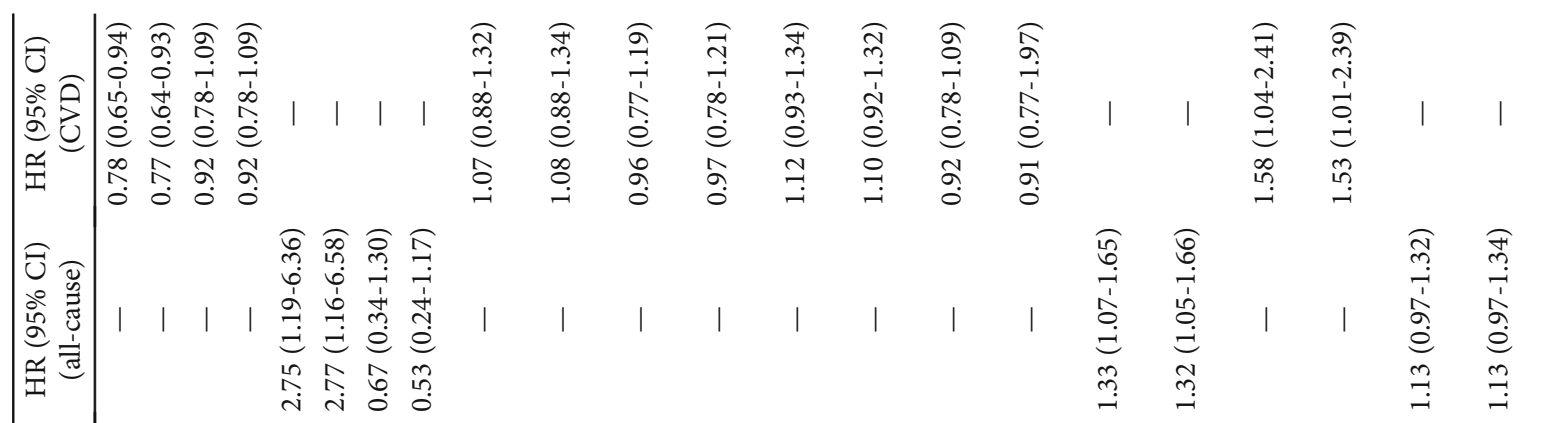

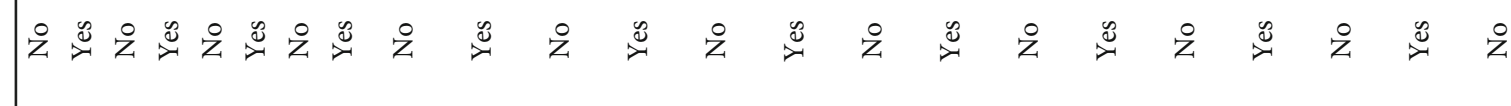

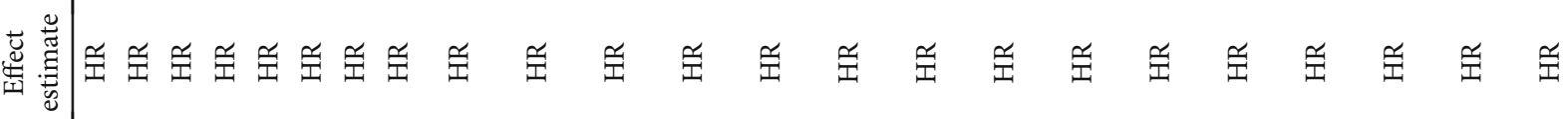

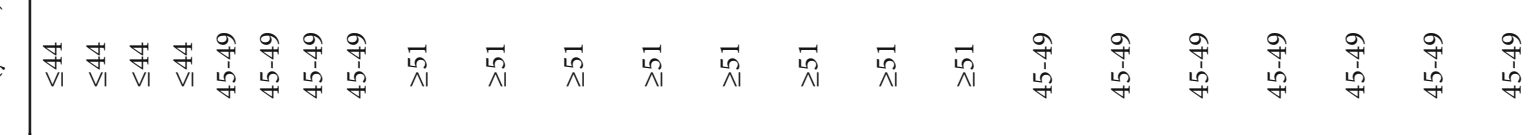

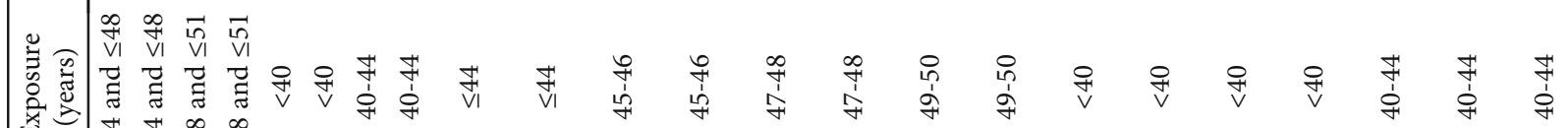

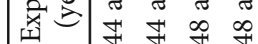

炃莺

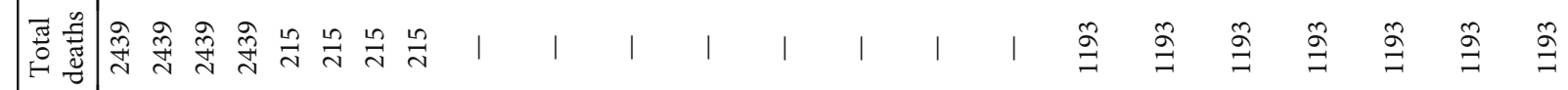

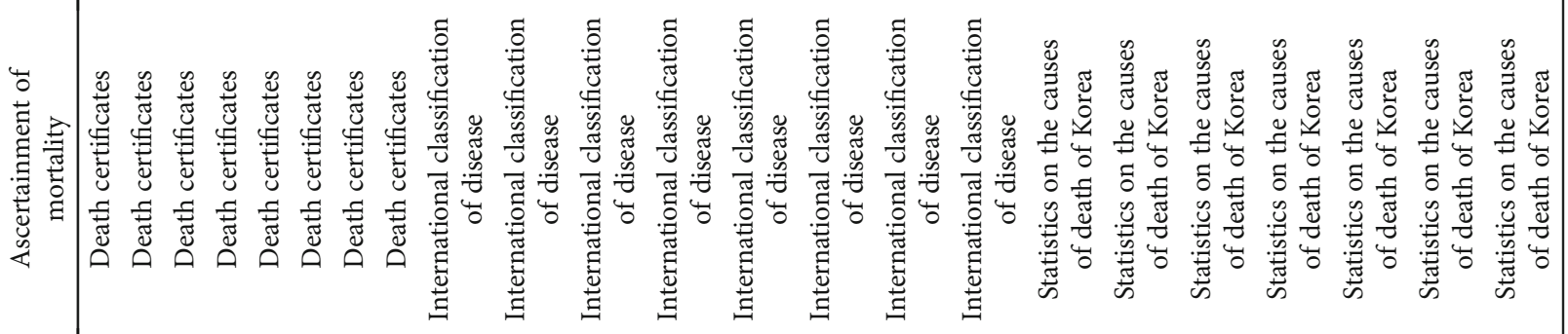

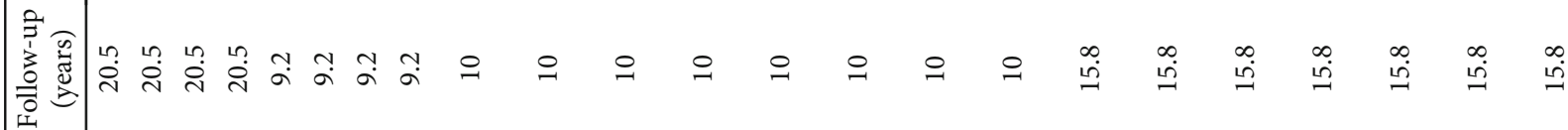

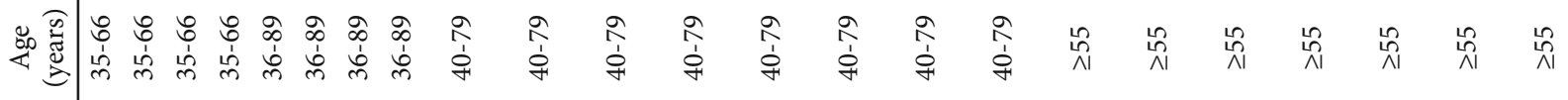

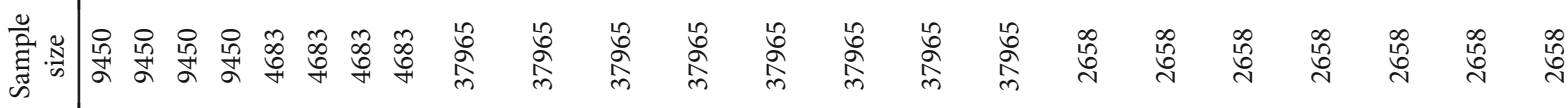

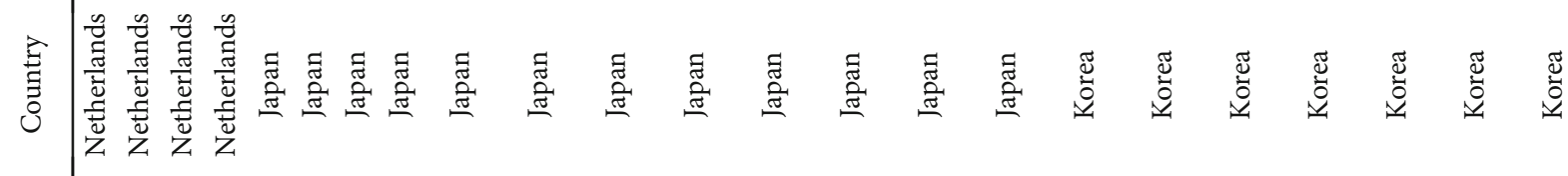

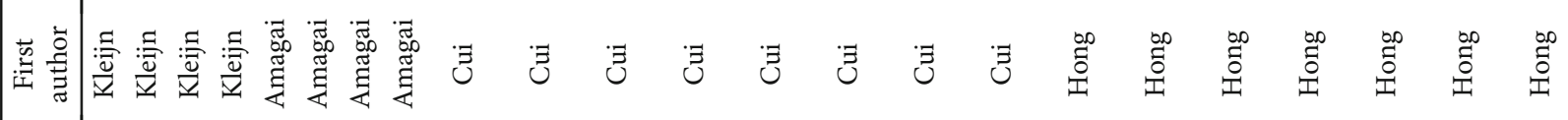

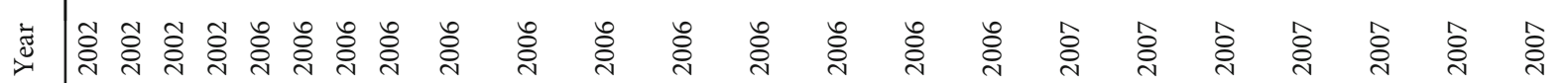




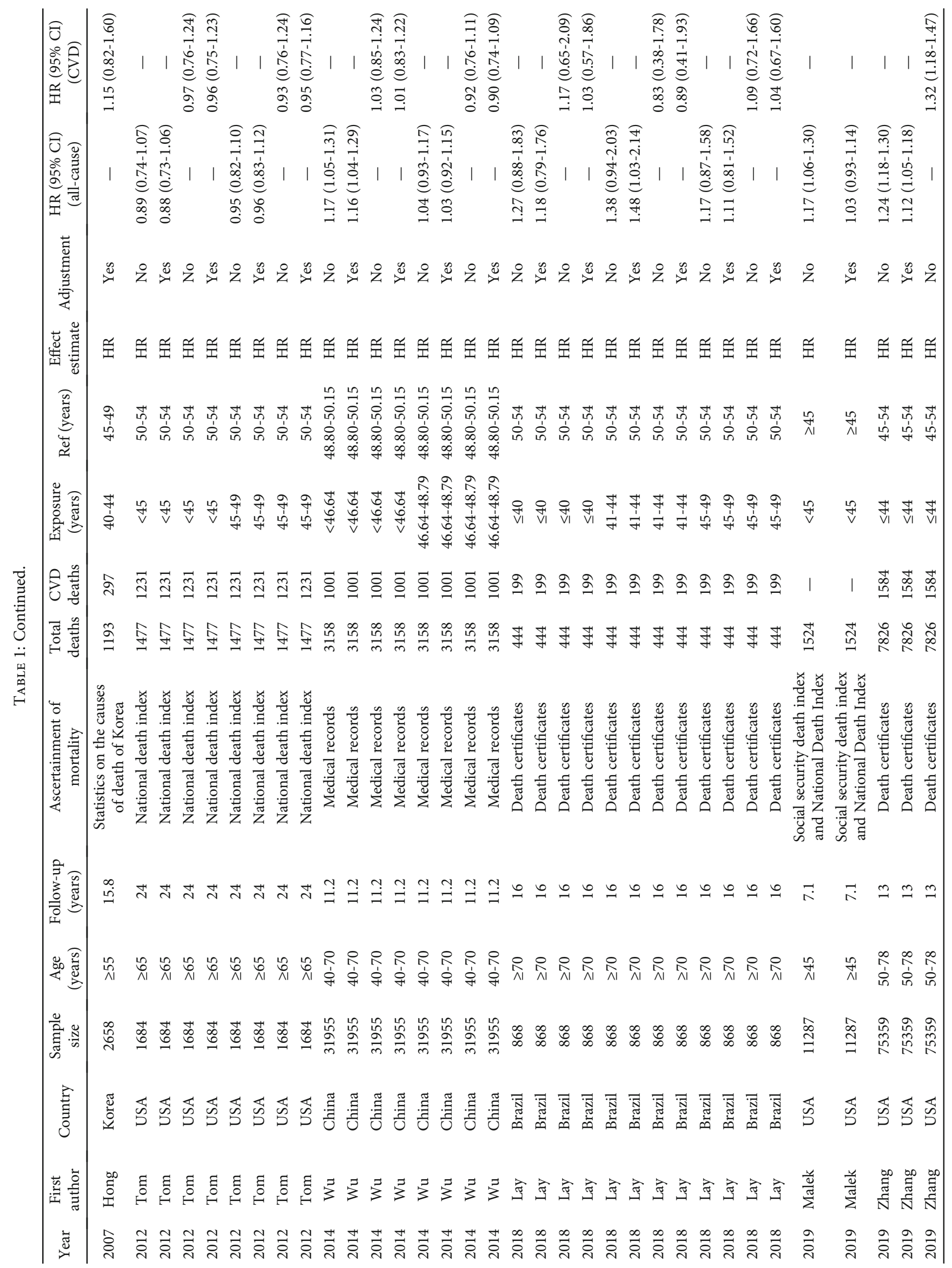




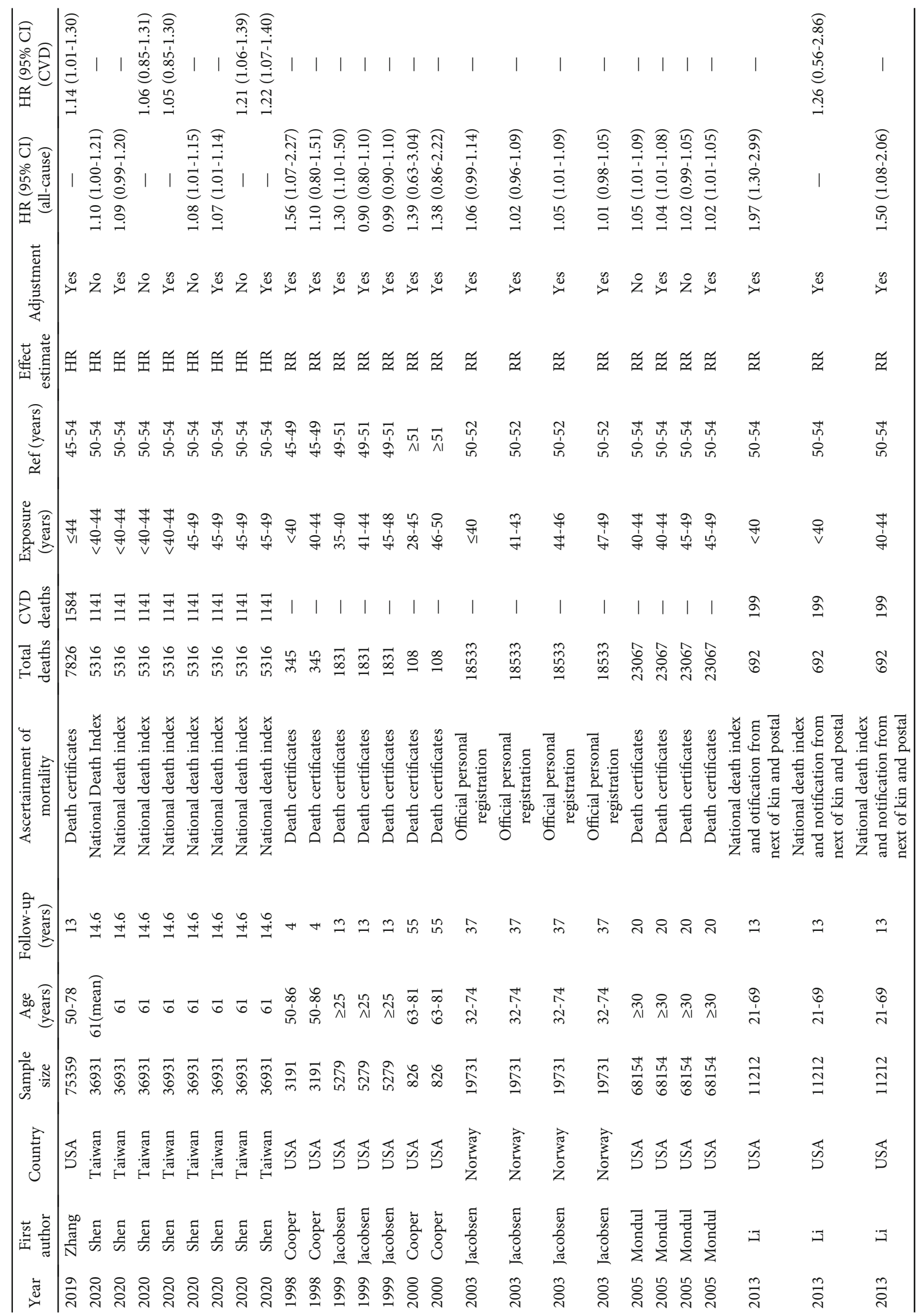




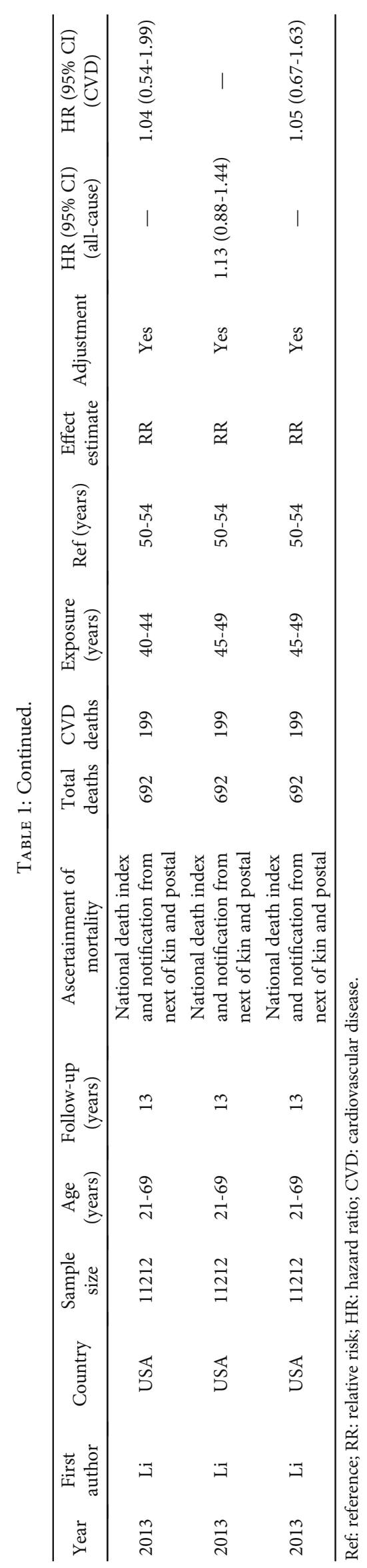


TABLE 2: The statistical methods of all involved studies in this meta-analysis.

\begin{tabular}{|c|c|c|c|c|c|c|c|}
\hline Year & $\begin{array}{l}\text { First } \\
\text { author }\end{array}$ & Country & $\begin{array}{l}\text { Sample } \\
\text { size }\end{array}$ & Study type & Statistical method & Adjustment for confounders & $\begin{array}{c}\text { Effect } \\
\text { estimate }\end{array}$ \\
\hline 2002 & Kleijn & Netherlands & 9450 & Cohort study & $\begin{array}{l}\text { Cox proportional } \\
\text { hazards model }\end{array}$ & $\begin{array}{l}\text { Age, hormone replacement therapy use, } \\
\text { hypertension, BMI, and social economic class. }\end{array}$ & HR \\
\hline 2006 & Amagai & Japan & 4683 & Cohort study & $\begin{array}{l}\text { Cox proportional } \\
\text { hazard model }\end{array}$ & $\begin{array}{l}\text { Age, SBP, TC, HDL-C, history of DB, BMI, } \\
\text { smoking, alcohol, marital status, study area, } \\
\text { and type of menopause. }\end{array}$ & HR \\
\hline 2006 & Cui & Japan & 37965 & Cohort study & $\begin{array}{l}\text { Cox proportional } \\
\text { hazard model }\end{array}$ & $\begin{array}{l}\text { Age, smoking, alcohol, marital status, type of } \\
\text { menopause, education, hypertension, and diabetes. }\end{array}$ & HR \\
\hline 2007 & Hong & Korea & 2658 & Cohort study & $\begin{array}{l}\text { Cox proportional } \\
\text { hazards model }\end{array}$ & $\begin{array}{l}\text { Age, alcohol consumption, education, age } \\
\text { at first birth, self-cognitive health level, chronic } \\
\text { disease, marital partner, parity, age at menarche, } \\
\text { oral contraceptive use, and hypertension. }\end{array}$ & $\mathrm{HR}$ \\
\hline 2012 & Tom & USA & 1684 & Cohort study & $\begin{array}{l}\text { Cox proportional } \\
\text { hazards model }\end{array}$ & $\begin{array}{l}\text { Age, education, pregnancy number, age at menarche, } \\
\text { smoking, height, weight, and use of ET. }\end{array}$ & HR \\
\hline 2014 & $\mathrm{Wu}$ & China & 31955 & Cohort study & $\begin{array}{l}\text { Cox proportional } \\
\text { hazard model }\end{array}$ & $\begin{array}{c}\text { Age at study enrollment, BMI, WHR, education, } \\
\text { occupation, income, regular exercise, current } \\
\text { smoking or alcohol, marital status, age at menarche, } \\
\text { and number of live births. }\end{array}$ & HR \\
\hline 2018 & Lay & Brazil & 868 & Cohort study & $\begin{array}{l}\text { Cox regression } \\
\text { model }\end{array}$ & $\begin{array}{c}\text { Social, year of birth, education, marital status, race, } \\
\text { reproductive, parity, smoking, number of chronic } \\
\text { diseases, and ET. }\end{array}$ & HR \\
\hline 2019 & Malek & USA & 11287 & Cohort study & $\begin{array}{l}\text { Cox proportional } \\
\text { hazards model }\end{array}$ & $\begin{array}{l}\text { Age, race, education, medical conditions, behavioral } \\
\text { characteristics, and type of menopause. }\end{array}$ & HR \\
\hline 2019 & Zhang & USA & 75359 & Cohort study & $\begin{array}{l}\text { Cox proportional } \\
\text { hazards model }\end{array}$ & $\begin{array}{l}\text { Baseline age, race, BMI, smoking, alcohol, marital } \\
\text { status, education level, physical exercise, hormone } \\
\text { replacement therapy use, CVD history, number of } \\
\text { live births, age at first birth, and type of menopause. }\end{array}$ & HR \\
\hline 2020 & Shen & Taiwan & 36931 & Cohort study & $\begin{array}{l}\text { Cox proportional } \\
\text { hazards model }\end{array}$ & $\begin{array}{c}\text { Birth cohort, education, smoking status, body mass } \\
\text { index, hypertension, diabetes, and high blood } \\
\text { cholesterol. }\end{array}$ & HR \\
\hline 1998 & Cooper & USA & 3191 & Cohort study & $\begin{array}{l}\text { Poisson } \\
\text { regression } \\
\text { procedures }\end{array}$ & $\begin{array}{l}\text { Age, education, race, smoking, use of estrogen } \\
\text { therapy, and years of follow-up. }\end{array}$ & $\mathrm{RR}$ \\
\hline 1999 & Jacobsen & USA & 5279 & Cohort study & $\begin{array}{l}\text { Proportional } \\
\text { hazards model }\end{array}$ & $\begin{array}{l}\text { DB, hypertension, parity, age at first birth, leisure PA, } \\
\text { education, BMI, current use of estrogen, ever- } \\
\text { smoking, vegetarian status, and dietary pattern. }\end{array}$ & $\mathrm{RR}$ \\
\hline 2000 & Cooper & USA & 826 & Cohort study & $\begin{array}{l}\text { Logistic } \\
\text { regression model }\end{array}$ & $\begin{array}{c}\text { Age, smoking, use of estrogen replacement therapy, } \\
\text { and parity. }\end{array}$ & $\mathrm{RR}$ \\
\hline 2003 & Jacobsen & Norway & 19731 & Cohort study & $\begin{array}{l}\text { Cox proportional } \\
\text { hazards model }\end{array}$ & Attained age, county, occupation, and birth cohort. & $\mathrm{RR}$ \\
\hline 2005 & Mondul & USA & 68154 & Cohort study & $\begin{array}{l}\text { Cox proportional } \\
\text { hazards model }\end{array}$ & $\begin{array}{l}\text { Age, race, marital status, BMI, age at menarche, } \\
\text { parity, education, alcohol, oral contraceptive use, } \\
\text { and exercise. }\end{array}$ & $\mathrm{RR}$ \\
\hline 2013 & $\mathrm{Li}$ & USA & 11212 & Cohort study & $\begin{array}{l}\text { Cox proportional } \\
\text { hazard model }\end{array}$ & $\begin{array}{l}\text { Age and time period, education, marital status, BMI, } \\
\text { smoking, alcohol, PE, dietary pattern, menarche } \\
\text { age, parity or first birth, reproductive factors, } \\
\text { contraceptive use, lactation duration, and } \\
\text { unilateral oophorectomy. }\end{array}$ & $\mathrm{RR}$ \\
\hline
\end{tabular}

RR: relative risk; HR: hazard ratio; BMI: body mass index; SBP: systolic blood pressure; CVD: cardiovascular disease; HDL-C: high-density lipoprotein cholesterol; PE: physical education; TC: total cholesterol; DB: diabetes mellitus; WHR: waist-to hip ratio; PA: physical activity.

$(\mathrm{RR}=1.03,95 \% \mathrm{CI}: 1.01$ to $1.08, P=0.010)$ (Two-sample $Z$ test $P=0.088)$. However, the association between early age at natural menopause and cardiovascular mortality was not statistically significant in American $(\mathrm{HR}=1.06$, 95\% CI: 0.97 to $1.16, P=0.235$; $\mathrm{RR}=1.08,95 \% \mathrm{CI}: 0.77$ to
$1.51, P=0.652)$, Europe $(\mathrm{HR}=0.85,95 \% \mathrm{CI}: 0.71$ to 1.01 , $P=0.060)$, and Asian $(\mathrm{HR}=1.05,95 \% \mathrm{CI}: 0.97$ to 1.14 , $P=0.228)$ countries.

In studies reporting $\mathrm{HR}$, by the median value (13.8 years) of follow-up intervals, the association of early age at natural 


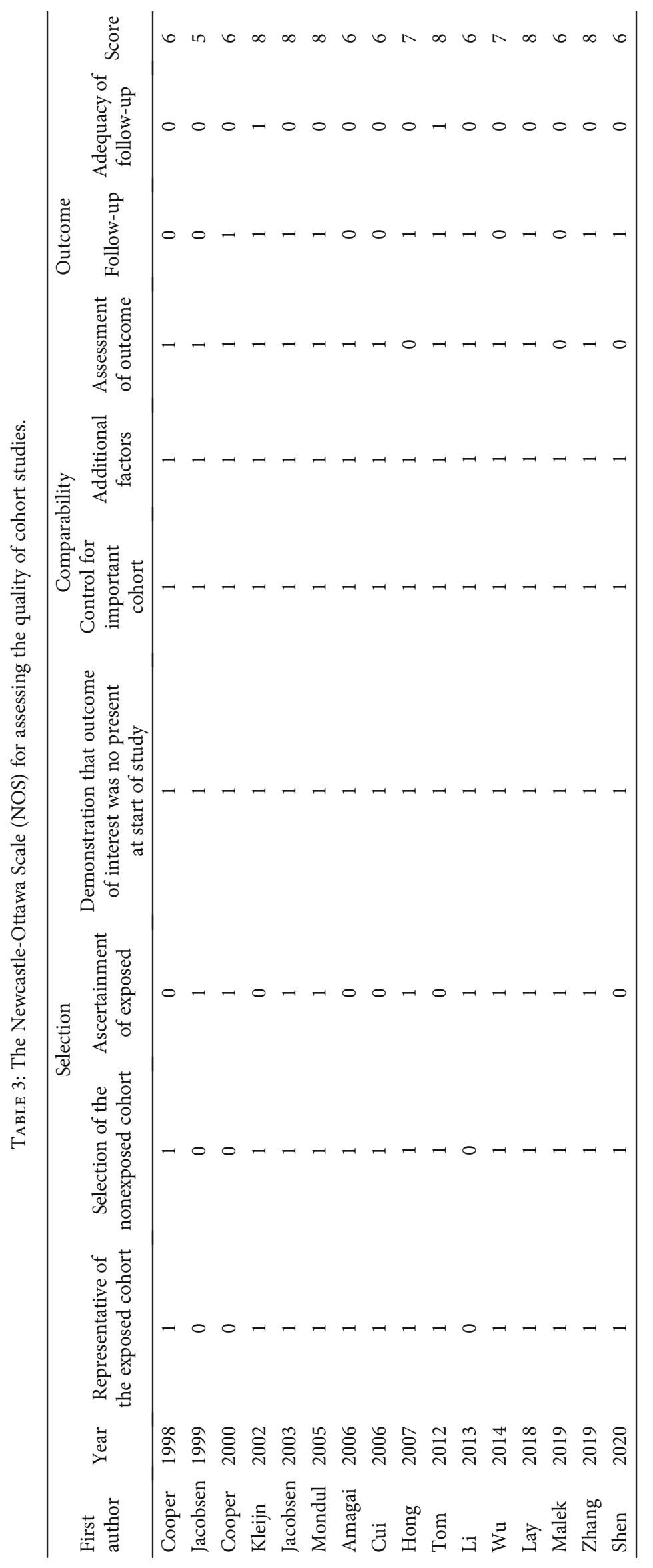


TABLE 4: Overall and subgroup analyses of early age at natural menopause with all-cause and cardiovascular mortality.

\begin{tabular}{|c|c|c|c|c|c|}
\hline \multirow{2}{*}{$\begin{array}{l}\text { Group } \\
\text { Effect-size estimate }\end{array}$} & \multirow[t]{2}{*}{ Studies $(\mathrm{n})$} & \multicolumn{2}{|c|}{ All-cause mortality } & \multicolumn{2}{|c|}{ Cardiovascular mortality } \\
\hline & & HR $(95 \%$ CI $) ; P$ & $I^{2}$ & HR $(95 \%$ CI $) ; P$ & $I^{2}$ \\
\hline \multicolumn{6}{|l|}{ Overall analyses } \\
\hline Mortality (unadjusted) & $15 / 18$ & $1.12(1.05-1.19) ;<0.001$ & $65.3 \%$ & 1.04 (1.00-1.13); 0.385 & $61.7 \%$ \\
\hline Mortality (adjusted) & $15 / 18$ & 1.08 (1.03-1.14); 0.002 & $45.6 \%$ & 1.01 (0.95-1.09); 0.682 & $42.1 \%$ \\
\hline \multicolumn{6}{|l|}{ Subgroup analyses } \\
\hline \multicolumn{6}{|l|}{ By country } \\
\hline America & $7 / 6$ & 1.05 (0.96-1.15); 0.268 & $51.5 \%$ & $1.06(0.96-1.16) ; 0.235$ & $0.0 \%$ \\
\hline Europe & $\mathrm{NA} / 2$ & $\mathrm{NA}$ & NA & 0.85 (0.71-1.01); 0.060 & $48.3 \%$ \\
\hline Asia & $8 / 10$ & 1.11 (1.03-1.18); 0.004 & $46.7 \%$ & $1.05(0.97-1.14) ; 0.228$ & $37.1 \%$ \\
\hline \multicolumn{6}{|l|}{ By follow-up } \\
\hline$<13.8$ years & $6 / 7$ & 1.09 (1.00-1.18); 0.047 & $57.7 \%$ & $1.02(0.95-1.10) ; 0.560$ & $20.6 \%$ \\
\hline$\geq 13.8$ years & $9 / 11$ & $1.08(1.01-1.16) ; 0.036$ & $40.0 \%$ & $1.01(0.90-1.14) ; 0.811$ & $54.0 \%$ \\
\hline \multicolumn{6}{|l|}{ Dose-response analysis } \\
\hline$<40$ years & $7 / 6$ & 1.10 (1.01-1.21); 0.034 & $60.7 \%$ & 1.09 (1.00-1.19); 0.045 & $0.0 \%$ \\
\hline 40-44 years & $4 / 3$ & 1.12 (0.96-1.31); 0.145 & $49.2 \%$ & 1.07 (0.90-1.27); 0.464 & $0.0 \%$ \\
\hline $45-49$ years & $4 / 9$ & 1.05 (1.00-1.10); 0.051 & $0.0 \%$ & 0.97 (0.88-1.07); 0.539 & $60.8 \%$ \\
\hline Effect-size estimate & & $\mathrm{RR}(95 \% \mathrm{CI}) ; P$ & $I^{2}$ & $\mathrm{RR}(95 \% \mathrm{CI}) ; P$ & $I^{2}$ \\
\hline \multicolumn{6}{|l|}{ Overall analyses } \\
\hline Mortality (unadjusted) & $2 / \mathrm{NA}$ & 1.03 (1.00-1.06); 0.026 & $28.2 \%$ & NA & NA \\
\hline Mortality (adjusted) & $16 / 3$ & 1.05 (1.01-1.08); 0.005 & $60.7 \%$ & $1.08(0.77-1.51) ; 0.652$ & $0.0 \%$ \\
\hline \multicolumn{6}{|l|}{ Subgroup analyses } \\
\hline \multicolumn{6}{|l|}{ By country } \\
\hline America & $12 / 3$ & $1.08(1.02-1.15) ; 0.010$ & $68.8 \%$ & $1.08(0.77-1.51) ; 0.652$ & $0.0 \%$ \\
\hline Europe & $4 / \mathrm{NA}$ & 1.03 (1.01-1.08); 0.010 & $0.0 \%$ & NA & NA \\
\hline Asia & NA/NA & $\mathrm{NA}$ & NA & NA & NA \\
\hline \multicolumn{6}{|l|}{ By follow-up } \\
\hline$<16.5$ years & $8 / 8$ & $1.21(1.03-1.41) ; 0.020$ & $76.0 \%$ & $1.08(0.77-1.51) ; 0.652$ & $0.0 \%$ \\
\hline$\geq 16.5$ years & $3 / \mathrm{NA}$ & $1.08(0.77-1.51) ; 0.652$ & $0.0 \%$ & NA & NA \\
\hline \multicolumn{6}{|l|}{ Dose-response analysis } \\
\hline$<40$ years & $5 / 1$ & 1.34 (1.08-1.66); 0.007 & $75.3 \%$ & $1.26(0.56-2.85) ; 0.579$ & NA \\
\hline 40-44 years & $5 / 1$ & 1.03 (0.96-1.10); 0.377 & $52.7 \%$ & $1.04(0.54-2.00) ; 0.906$ & NA \\
\hline $45-49$ years & $6 / 1$ & 1.02 (1.01-1.04); 0.004 & $0.0 \%$ & 1.05 (0.67-1.64); 0.830 & NA \\
\hline
\end{tabular}

HR: hazard ratio; RR: relative risk; 95\% CI: 95\% confidence interval; NA: not available.

menopause with all-cause mortality was significant in both short $(<13.8$ years $)(\mathrm{HR}=1.09,95 \% \mathrm{CI}: 1.00$ to $1.18, P=$ $0.047)$ and long $(\geq 13.8$ years) $(\mathrm{HR}=1.08,95 \% \mathrm{CI}: 1.01$ to $1.16, P=0.036)$ follow-ups. By contrary, in studies reporting $\mathrm{RR}$, by the median value (16.5 years) of follow-up intervals, the association of early age at natural menopause with allcause mortality was significant in short ( $<16.5$ years) ( $\mathrm{RR}=1.21,95 \% \mathrm{CI}: 1.03$ to $1.41, P=0.020)$, but not in long ( $\geq 16.5$ years $)(\mathrm{RR}=1.08,95 \% \mathrm{CI}: 0.77$ to $1.51, P=0.652)$ follow-ups. The association of early age at natural menopause with cardiovascular mortality was not significant in long ( $\geq 13.8$ years) $(\mathrm{HR}=1.01,95 \% \mathrm{CI}: 0.90$ to $1.14, P=0.811)$ and short $(<13.8$ years $)(\mathrm{HR}=1.02,95 \% \mathrm{CI}: 0.95$ to $1.10, P$ $=0.560$ ) follow-ups in studies reporting HR. Meanwhile, in studies reporting $\mathrm{RR}$, the association of early age at natural menopause with cardiovascular mortality was not significant.
3.6. Dose-Response Analyses. In the dose-response analysis of all-cause mortality in studies reporting HR, the association of premature menopause with all-cause mortality was significant $(\mathrm{HR}=1.10,95 \% \mathrm{CI}: 1.01$ to $1.21, P=0.034)$, but not for early $(\mathrm{HR}=1.12,95 \% \mathrm{CI}$ : 0.96 to $1.31, P=0.145)$ and relatively early menopause $(\mathrm{HR}=1.05,95 \% \mathrm{CI}: 1.00$ to $1.10, P=0.051)$. In studies reporting $\mathrm{RR}$, women with premature menopause $(\mathrm{RR}=1.34,95 \% \mathrm{CI}: 1.08$ to $1.66, P=$ $0.007)$ had a higher risk than women with relatively early menopause $(\mathrm{RR}=1.02,95 \% \mathrm{CI}: 1.01$ to $1.04, P=0.004)$ (Two-sample $Z$ test $P=0.010$ ) for all-cause mortality.

In the dose-response analysis of cardiovascular mortality in studies reporting HR, the association was only significant for premature menopause $(\mathrm{HR}=1.09,95 \% \mathrm{CI}: 1.00$ to $1.19, P=0.045)$. However, in studies reporting RR, no statistical significance was observed across age groups in 


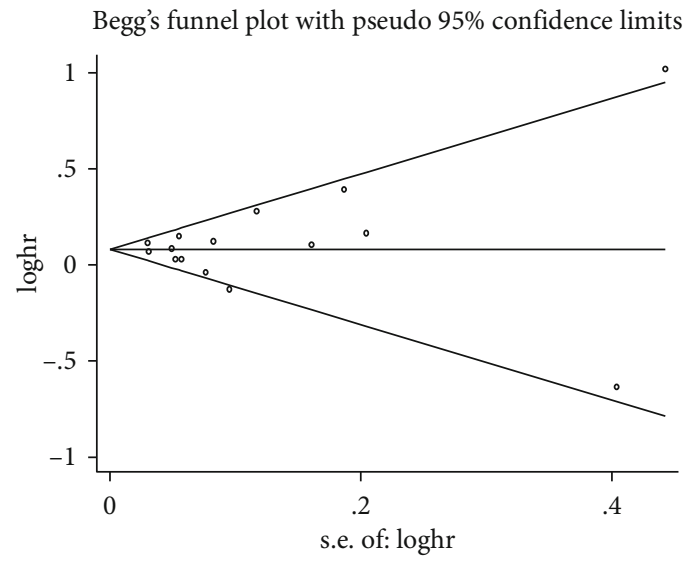

(a)

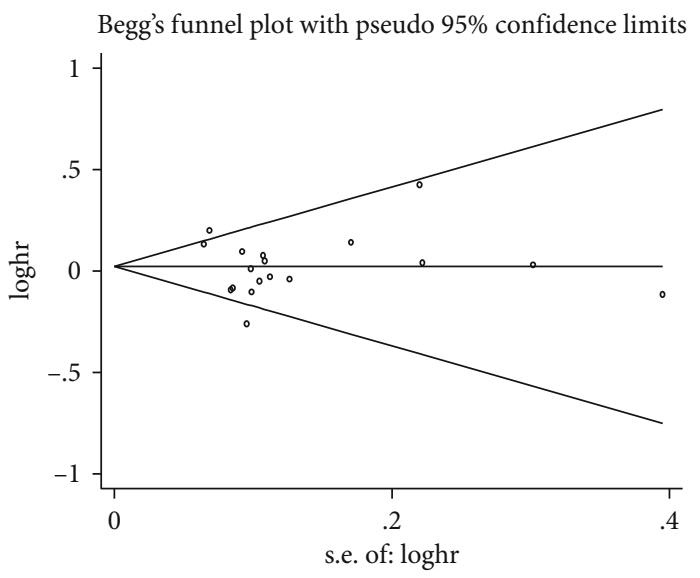

(c)

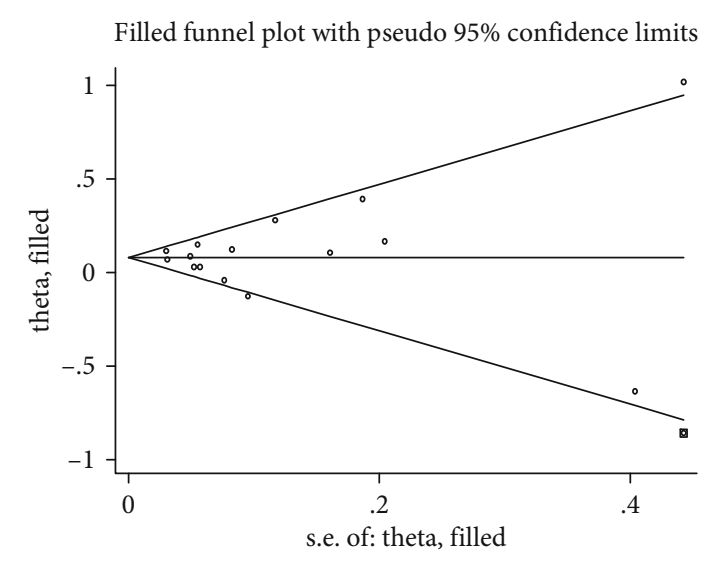

(b)

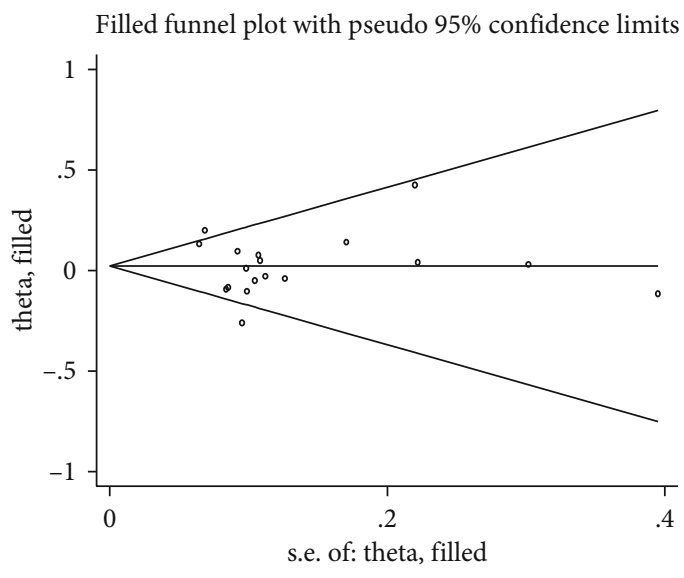

(d)

FIGURE 2: The Begg's and filled funnel plots on the association of early age at natural menopause with all-cause and cardiovascular mortality in studies reporting hazard ratio (HR) as effect-size estimates. (a) Begg's funnel plot and (b) filled funnel plot: all-cause mortality (HR). (c) Begg's funnel plot and (d) filled funnel plot: cardiovascular mortality (HR).

cardiovascular mortality (<40 years: $\mathrm{RR}=1.26,95 \% \mathrm{CI}: 0.56$ to $2.85, P=0.579 ; 40-44$ years: $\mathrm{RR}=1.04,95 \% \mathrm{CI}: 0.54$ to $2.00, P=0.906 ; 45-49$ years: $\mathrm{RR}=1.05,95 \% \mathrm{CI}: 0.67$ to $1.64, P=0.830)$.

\section{Discussion}

Via a comprehensive meta-analysis of 16 articles and 321,233 women, our findings indicate that premature menopause is a promising independent risk factor for both all-cause and cardiovascular mortality. Moreover, gender, country, and follow-up periods were identified as possible causes of between-study heterogeneity. To the best of our knowledge, this is the most comprehensive report that has metaanalyzed the prediction of early age at natural menopause for all-cause and cardiovascular mortality risk.

In 2016, Gong and colleagues in a meta-analysis of 10 articles investigated the association of early age at natural menopause with all-cause and cardiovascular mortality risk, and they found that the earliest age at natural menopause ( $<40$ years) was associated with a slightly increase in allcause mortality, but not with cardiovascular and strokerelated mortality [8]. In addition, they also found that women with natural menopause before 40 years of age had an $18 \%$ greater risk of all-cause mortality, and this relationship was not statistically significant in women with natural menopause before age 46.7 years [8]. The findings of the current meta-analysis on 16 articles reinforced that of the metaanalysis by Gong and colleagues [8], by reinforcing that early age at natural menopause was associated with a slightly increased risk of all-cause mortality. However, by further subdividing age of early menopause into three groups and different reports of study results into HRs and RRs, our findings indicated that premature menopause was more strongly associated with all-cause mortality than early natural menopause and relatively early natural menopause. Extending the findings of the meta-analysis by Gong and colleagues [8], as expected, we reported that early age at natural menopause was not significantly associated with cardiovascular mortality. More importantly, using the relatively large number of eligible articles, we further explored possible causes of between-study heterogeneity by conducting a wide panel of subgroup analyses.

Our finding on the association of natural menopause age before 40 years with increased all-cause mortality risk supports the hypothesis that premature natural menopause 
may serve as a marker of accelerated reproductive and somatic aging, as well as causing premature death [12]. Meantime, the timing of menopause reflects a complex interplay of genetic, epigenetic, socioeconomic, and lifestyle factors [32]. Several mechanisms have been proposed to interpret the association between earlier menopause and an increased risk of all-cause mortality, and the most promising reason may be lack of estrogen. Estrogens are potent vasoactive hormones that promote vascular remodeling and elasticity, and they can regulate reactive dilation and local inflammatory activity [33], as well as endothelial vasodilator dysfunction after estrogen deficiency [34, 35]. Estrogens also play a key role in the regulation of calcium homeostasis, and thus fine-tuning the normal process of cardiomyocyte contraction and relaxation [36]. Of course, it has also been suggested that this increased risk is associated with an increase in luteinizing hormone [37] or modulation of $\mathrm{T}$ cells [38].

Epidemiological studies have shown that premature menopause before 40 years of age affects about $1 \%$ of women [4], and as demonstrated in the current meta-analysis, the risk for all-cause mortality was greatest for women with premature menopause. The possible reasons lie in that earlier loss of the ovarian function can lead to long-term activation of the renin-angiotensin-aldosterone system, endothelial dysfunction, inflammation and immune dysfunction, and further acceleration of the occurrence or progression of chronic diseases, ending with the predisposition to allcause mortality [9, 39]. Furthermore, menopause marks the beginning of a biological mechanism caused by hormonal changes leading to tissue damage and organ dysfunction [40], and premature menopause is the earlier onset of this biological mechanism.

There are several possible limitations for the current meta-analysis. Firstly, because only published articles were retrieved and the "grey" literature (articles in languages other than the English) was not incorporated, publication bias is possible. Additionally, as the number of studies reporting $\mathrm{RR}$ as effect-size estimates is less than 10 in this meta-analysis, the power to detect statistical significance is low [41]. Secondly, age at menopause was self-reported, and misclassification of the groups by age at menopause cannot be excluded. Thirdly, women in these studies were limited only to natural menopause, and we did not address the effect of surgical menopause or medical interventions that induced menopause-relevant mortality.

\section{Conclusions}

Our findings indicated that premature menopause is a promising independent risk factor for both all-cause and cardiovascular mortality. To date, the most effective treatment is still hormone replacement therapy, yet this method may increase the incidence of more serious concerns such as venous thromboembolism and cancer [42]. Therefore, investigations on the mechanisms and therapies between early age at menopause and all-cause mortality are also warranted.

\section{Abbreviations}

CVD: $\quad$ Cardiovascular disease

EMBASE: Excerpt Medica Database

HR: Hazard ratio

RR: $\quad$ Risk ratio

CI: $\quad$ Confidence interval

$I^{2}: \quad$ Inconsistency index

PRISMA: Preferred Reporting Items for Systematic Reviews and Meta-analyses.

\section{Ethical Approval}

Ethical approval is waived for the present study because this is a meta-analysis based on the results of individual studies that had been reviewed and approved by localized ethics committees.

\section{Conflicts of Interest}

The authors declare that they have no conflicts of interests.

\section{Authors' Contributions}

Luyao Huan and Xiangling Deng shared first authors.

\section{Supplementary Materials}

Supplementary Table 1: the PRISMA checklist for all included studies in this meta-analysis. Supplementary Figure 1: Begg's and filled funnel plots on the association of early age at natural menopause with all-cause and cardiovascular mortality in studies reporting relative risk (RR) as effect-size estimates. (Supplementary Materials)

\section{References}

[1] R. J. Baber, "East is east and west is west: perspectives on the menopause in Asia and the west," Climacteric : the journal of the International Menopause Society, vol. 17, no. 1, pp. 2328, 2014.

[2] A. Morabia, M. C. Costanza, and World Health Organization Collaborative Study of Neoplasia and Steroid Contraceptives, "International variability in ages at menarche, first livebirth, and menopause. World Health Organization collaborative study of neoplasia and steroid contraceptives," American Journal of Epidemiology, vol. 148, no. 12, pp. 1195-1205, 1998.

[3] J. L. Shifren and M. L. S. Gass, "The North American Menopause Society recommendations for clinical care of midlife women," Menopause, vol. 21, no. 10, pp. 1038-1062, 2014.

[4] J. L. Luborsky, P. Meyer, M. F. Sowers, E. B. Gold, and N. Santoro, "Premature menopause in a multi-ethnic population study of the menopause transition," Human reproduction (Oxford, England), vol. 18, no. 1, pp. 199-206, 2003.

[5] M. C. Honigberg, S. M. Zekavat, K. Aragam et al., "Association of premature natural and surgical menopause with incident cardiovascular disease," JAMA, vol. 322, no. 24, p. 2411, 2019.

[6] D. A. Snowdon, R. L. Kane, W. L. Beeson et al., "Is early natural menopause a biologic marker of health and aging?," American Journal of Public Health, vol. 79, no. 6, pp. 709-714, 1989. 
[7] D. Zhu, H. F. Chung, A. J. Dobson et al., "Age at natural menopause and risk of incident cardiovascular disease: a pooled analysis of individual patient data," The Lancet Public Health, vol. 4, no. 11, pp. e553-e564, 2019.

[8] D. Gong, J. Sun, Y. Zhou, C. Zou, and Y. Fan, "Early age at natural menopause and risk of cardiovascular and all-cause mortality: a meta-analysis of prospective observational studies," International Journal of Cardiology, vol. 203, pp. 115-119, 2016.

[9] T. Muka, C. Oliver-Williams, S. Kunutsor et al., "Association of age at onset of menopause and time since onset of menopause with cardiovascular outcomes, intermediate vascular traits, and all-cause mortality: a systematic review and metaanalysis,” JAMA Cardiology, vol. 1, no. 7, pp. 767-776, 2016.

[10] T. Y. Shen, C. Strong, and T. Yu, "Age at menopause and mortality in Taiwan: a cohort analysis," Maturitas, vol. 136, pp. 42-48, 2020.

[11] Y. T. van der Schouw, Y. van der Graaf, E. W. Steyerberg, J. C. Eijkemans, and J. D. Banga, "Age at menopause as a risk factor for cardiovascular mortality," Lancet, vol. 347, no. 9003, pp. 714-718, 1996.

[12] S. Li, L. Rosenberg, L. A. Wise, D. A. Boggs, M. LaValley, and J. R. Palmer, "Age at natural menopause in relation to all-cause and cause-specific mortality in a follow-up study of US black women," Maturitas, vol. 75, no. 3, pp. 246-252, 2013.

[13] F. Atsma, M. L. Bartelink, D. E. Grobbee, and Y. T. van der Schouw, "Postmenopausal status and early menopause as independent risk factors for cardiovascular disease: a metaanalysis," Menopause (New York, NY), vol. 13, no. 2, pp. 265-279, 2006.

[14] D. Moher, A. Liberati, J. Tetzlaff, and D. G. Altman, "Preferred reporting items for systematic reviews and meta-analyses: the PRISMA statement," PLoS Medicine, vol. 6, no. 7, article e1000097, 2009.

[15] G. Wells, B. Shea, and J. O'Connell, "The Newcastle-Ottawa scale (NOS) for assessing the quality of nonrandomised studies in meta-analyses," Ottawa Health Research Institute Web site, vol. 7, 2014.

[16] C. B. Begg and M. Mazumdar, "Operating characteristics of a rank correlation test for publication bias," Biometrics, vol. 50, no. 4, pp. 1088-1101, 1994.

[17] M. Egger, G. Davey Smith, M. Schneider, and C. Minder, "Bias in meta-analysis detected by a simple, graphical test," BMJ (Clinical research ed), vol. 315, no. 7109, pp. 629-634, 1997.

[18] J. S. Hong, S. W. Yi, H. C. Kang et al., "Age at menopause and cause-specific mortality in South Korean women: Kangwha cohort study," Maturitas, vol. 56, no. 4, pp. 411-419, 2007.

[19] A. M. Malek, C. J. Vladutiu, M. L. Meyer et al., "The association of age at menopause and all-cause and cause-specific mortality by race, postmenopausal hormone use, and smoking status," Preventive Medical Reports, vol. 15, p. 100955, 2019.

[20] A. A. R. Lay, C. F. do Nascimento, Y. A. de Oliveira Duarte, and A. D. P. C. Filho, "Age at natural menopause and mortality: a survival analysis of elderly residents of São Paulo, Brazil," Maturitas, vol. 117, pp. 29-33, 2018.

[21] S. E. Tom, R. Cooper, R. B. Wallace, and J. M. Guralnik, "Type and timing of menopause and later life mortality among women in the Iowa Established Populations for the Epidemiological Study of the Elderly (EPESE) cohort," Journal of women's health, vol. 21, no. 1, pp. 10-16, 2012.
[22] X. Zhang, L. Liu, F. Song, Y. Song, and H. Dai, “Ages at menarche and menopause, and mortality among postmenopausal women," Maturitas, vol. 130, pp. 50-56, 2019.

[23] Y. Amagai, S. Ishikawa, T. Gotoh, K. Kayaba, Y. Nakamura, and E. Kajii, "Age at menopause and mortality in Japan: the Jichi Medical School cohort study," Journal of Epidemiology, vol. 16, no. 4, pp. 161-166, 2006.

[24] G. S. Cooper and D. P. Sandler, "Age at natural menopause and mortality," Annals of Epidemiology, vol. 8, no. 4, pp. 229-235, 1998.

[25] R. Cui, H. Iso, H. Toyoshima et al., "Relationships of age at menarche and menopause, and reproductive year with mortality from cardiovascular disease in Japanese postmenopausal women: the JACC study," Journal of Epidemiology, vol. 16, no. 5, pp. 177-184, 2006.

[26] M. J. de Kleijn, Y. T. van der Schouw, A. L. Verbeek, P. H. Peeters, J. D. Banga, and Y. van der Graaf, "Endogenous estrogen exposure and cardiovascular mortality risk in postmenopausal women," American Journal of Epidemiology, vol. 155, no. 4, pp. 339-345, 2002.

[27] A. M. Mondul, C. Rodriguez, E. J. Jacobs, and E. E. Calle, "Age at natural menopause and cause-specific mortality," American Journal of Epidemiology, vol. 162, no. 11, pp. 1089-1097, 2005.

[28] G. S. Cooper, D. D. Baird, C. R. Weinberg, S. A. Ephross, and D. P. Sandler, "Age at menopause and childbearing patterns in relation to mortality," American Journal of Epidemiology, vol. 151, no. 6, pp. 620-623, 2000.

[29] B. K. Jacobsen, S. F. Knutsen, and G. E. Fraser, "Age at natural menopause and total mortality and mortality from ischemic heart disease: the Adventist health study," Journal of Clinical Epidemiology, vol. 52, no. 4, pp. 303-307, 1999.

[30] X. Wu, H. Cai, A. Kallianpur et al., "Age at menarche and natural menopause and number of reproductive years in association with mortality: results from a median follow-up of 11.2 years among 31,955 naturally menopausal Chinese women," PloS one, vol. 9, no. 8, 2014.

[31] B. K. Jacobsen, I. Heuch, and G. Kvale, "Age at natural menopause and all-cause mortality: a 37-year follow-up of 19,731 Norwegian women," American Journal of Epidemiology, vol. 157, no. 10, pp. 923-929, 2003.

[32] S. R. Davis, I. Lambrinoudaki, M. Lumsden et al., "Menopause," Nature reviews Disease primers, vol. 1, no. 1, 2015.

[33] F. G. Hage and S. Oparil, "Ovarian hormones and vascular disease," Current Opinion in Cardiology, vol. 28, no. 4, pp. 411416, 2013.

[34] Y. B. Somani, J. A. Pawelczyk, M. J. De Souza, P. M. KrisEtherton, and D. N. Proctor, "Aging women and their endothelium: probing the relative role of estrogen on vasodilator function," American Journal of Physiology Heart and Circulatory Physiology, vol. 317, no. 2, pp. H395-h404, 2019.

[35] A. A. Miragem and P. I. H. de Bittencourt, "Nitric oxide-heat shock protein axis in menopausal hot flushes: neglected metabolic issues of chronic inflammatory diseases associated with deranged heat shock response," Human Reproduction Update, vol. 23, no. 5, pp. 600-628, 2017.

[36] L. Jiao, J. Ong'achwa Machuki, Q. Wu et al., "Estrogen and calcium handling proteins: new discoveries and mechanisms in cardiovascular diseases," American Journal of Physiology Heart and Circulatory Physiology, vol. 318, no. 4, pp. H820-h829, 2020. 
[37] D. Kim, Q. F. Liu, H. J. Jeong, S. H. Han, D. I. Kim, and S. Jeon, "A modified formulation of Sutaehwan ameliorates menopausal anxiety, depression and heart hypertrophy in the VCD-induced menopausal mouse model," Biological \& Pharmaceutical Bulletin, vol. 42, no. 9, pp. 1471-1481, 2019.

[38] D. P. Pollow Jr., J. A. Uhlorn, M. A. Sylvester et al., "Menopause and FOXP3(+) Treg cell depletion eliminate female protection against T cell-mediated angiotensin II hypertension," American Journal of Physiology Heart and Circulatory Physiology, vol. 317, no. 2, pp. H415-h423, 2019.

[39] Z. Zhao, H. Wang, J. A. Jessup, S. H. Lindsey, M. C. Chappell, and L. Groban, "Role of estrogen in diastolic dysfunction," American Journal of Physiology Heart and Circulatory Physiology, vol. 306, no. 5, pp. H628-H640, 2014.

[40] W. A. Rocca, L. T. Shuster, B. R. Grossardt et al., "Long-term effects of bilateral oophorectomy on brain aging: unanswered questions from the Mayo Clinic Cohort Study of Oophorectomy and Aging," Women's health (London, England), vol. 5, no. 1, pp. 39-48, 2009.

[41] https://handbook-5-1.cochrane.org/chapter_10/10_4_3_1_ recommendations_on_testing_for_funnel_plot_asymmetry .htm.

[42] R. A. Lobo, "Hormone-replacement therapy: current thinking," Nature Reviews Endocrinology, vol. 13, no. 4, pp. 220231, 2017. 